\title{
Analysis of Internet of Things Talent Training and Curriculum System Innovation
}

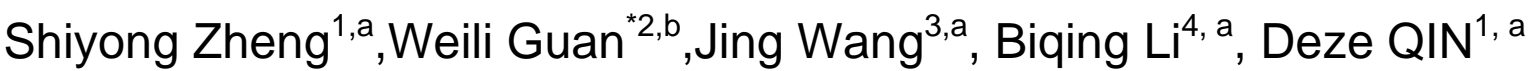 \\ ${ }^{1}$ School of Computer Science and Information Engineering, Hezhou university, Hezhou \\ Guangxi 542899, China; \\ ${ }^{2}$ College of Information Engineering, Nanning university, Nanning Guangxi 530200, China; \\ ${ }^{3}$ School of Economics and Management, Hezhou university, Hezhou Guangxi 542899, China \\ ${ }^{4}$ School of Mechanical and Electronic Engineering, Hezhou university, Hezhou Guangxi \\ 542899, China \\ ajanliful@163.com, b 13508326@qq.com \\ Corresponding Author: Weili Guan
}

Keywords: Internet of things; Training program; Curriculum innovation

\begin{abstract}
Analyze the restrictive factors of Internet of things major in the curriculum system in according with present market demand situation of Internet of things talent. It is suggested that practice be combined with theory. Students' practice ability should be improved. Diverse curriculum should be created and a new training mode and training objective should be established to improve teaching effect of Internet of things major curriculum.
\end{abstract}

\section{Background}

Internet of things technology can promote commercial profit. Internet of things and cloud computing are regarded as important direction of computer network, having great market value. At present, America, EU, Japan and other developed countries are having made detail plans in Internet of things talent cultivation and gradually make it come true. Meanwhile, to adapt to the market demand, China also devotes greater effort in education, renewing educational concept. It requires that vocational education combine with industry development. And the program is updated in the process of development. Strengthen corresponding major training to prepare for the social talent transformation. Setting up corresponding courses makes it easier for the learners to find correct position, to meet the demand of Internet of things market.

\section{Teaching situation analysis of present course}

Those who specialize in Internet of things major are the major enrollment so that this major carries great weight in all university majors. However, the present course teaching situation is not satisfactory. Information industry era has been renewed, while the teaching quality does not. The reality is always being like that: give attention to theory but not to practice. The teaching process always has much to do with the book.

\section{Internet of things talent training and implementation plan}

\subsection{Training objective}

Main objectives of Internet of things training:1, need the strong participation of enterprises in the process of training; 2, colleges and universities should redo the admission requirements, having good standard and choice in talent training; 3, strengthen students' independent practical ability. Do combine practice with theory. Always make breakthrough and pursue innovation. 


\subsection{Training process}

The whole training process consists of first-phase preparations, the adoption of the joint program of the colleges and enterprises, campus talent selection, the organized training of the enterprise and induction training. First-phase preparations require to visit practice base, totally understand what kinds of talents the enterprises need, clear out the prepared program between the enterprises and sign a contract. Cooperation between colleges and enterprises existing the whole process. It requires colleges to conclude scientific courses, enterprises to offer chances and places to practice. It effectively shortens the distance between colleges and talent market demand, laying the foundation for this talent training program.

\subsection{Concrete measures}

According to the previous description, the development of Internet of things not only needs a series of talent training program, but also needs innovation in teaching. The old teaching situation does not meet the demand of present talent market. In order to keep the pace of era, computer talents must be gradually promoted. Course teaching reformation in Internet of things major is needed.

3.3.1 Strengthen teaching aims of course outline and update design of course content to meet the demand of talent market.

Theory teaching is an important part. It can guide students to learn well. An excellent layout of contents has conclusive function to establish a course. National ministry of education has concrete requirements in every major, and detailed stipulation in course design. Colleges have to abide by the course stipulation formulated by national ministry of education, however, they can properly develop the contents of the textbook and add interest. They can also keep up with the information time and introduce related technology knowledge. Therefore, the most advanced technology can be blended in textbook to students know more the latest technology achievements

\subsubsection{Effective use of limited teaching resources for training}

Iot (Internet of things) professional learning is like a complex roadmap. It really needs reasonable, appropriate and correct course. Start from the base layer. Firstly, every referred knowledge point of this major should be introduced, and students should be told important points of every chapter. Secondly, the teacher should give students some time to prepare lessons before class to make preparation for deep learning. Thirdly, students should do related exercises after class or in their spare time, by which they can know which point or definition they are not familiar with or do not understand, then they relearn the textbook. Finally, after doing exercises, they can check whether right or wrong by making use of the referenced answers, if wrong, they can look at the detailed explanation which quickly let them know why they are wrong and remind them to be careful next time.

3.3.3 Strengthen the teaching level and improve teaching efficiency.

A good teaching establishment not only needs compiling course and sufficient teaching resources, but also an excellent teaching team. Therefore, the stand or fall teaching level directly affects the students' test scores even teaching quality. As a result, reformation can be started from the following aspects: firstly, educational background exaltation of teachers is really needed. Though academic background cannot stand for a person's knowledge, advanced degree can make a college be more attractive.

3.3.4 Strengthening the cultivation of students' practice ability and innovation ability.

In the past, teachers paid a lot of attention to theory but less to practice, so even students know much about theory but they have really weak practice ability that when they graduate from college they still find it hard to seek a related job. As a result, strengthening the cultivation of students' practice ability and innovation ability is definitely needed.

(1) Increase input in equipment and strengthen practice

Since 2008, central and local governments and schools reach a consensus: build up university laboratory and increase input. Provide students with good learning environment. All these offer great resources to learn Iot major. And it not only effectively strengthens students' practice ability, but also cultivates their practice interest. 
(2) Strengthen the application of the Internet and strengthen the Internet system to make it convenient for students to learn by themselves.

Establishing online learning system is not so easy. It needs to devote greater effort in design. Online learning does not mean relearn what do in class, but it refers to expansion. Online learning gives students much convenience. For those who have wide learning interest, online learning is a library.

3.3.5 The change of university achievement evaluation

Achievement evaluation is the checkout of what the students have learned in a certain time. Thus, achievement evaluation is a significant link in education field. The reforming aims of university achievement evaluation are to make students pay attention to details during learning process, arouse students' learning interest and improve learning efficiency. University achievement evaluation reformations are following: the proportion of daily grades increases to $50 \% \sim 60 \%$, while the proportion of final exam scores decreases to $40 \% \sim 50 \%$. There are also some changes in regular assignments. For example, there may be some small topic reports and essays.

\section{Conclusion}

Iot major is a hot major. To meet the need of the talent market, innovation and improvement have been conducted from teaching course to students' practice. By these powerful reforms a series of course changes have been established. The teachers also change teaching methods. They make the most of teaching resources and strengthen students' practice ability and innovation ability so increase knowledge level and cultivate students' positivity. At the same time, university achievement evaluation has been adjusted to increase students' learning interest and stimulate motivation and then then promote learning efficiency.

\section{Acknowledgements}

This work is supported the following fund :

Guangxi science and technology development projects, Tourism security key technology and development of new products research (No 1355009-9);

Project of scientific research and technology development project of Hezhou: "Design and implementation of agricultural products e-commerce platform based on Semantic Technology" (No,Hekeneng 1506006)

Guangxi science and technology development plan (No 11107006-13 \&\&No 12118017-10A);

Nanning scientific research and technology development project(No 20121033);

Nanning science and technology development plan project of Yongning district(No 20130332D);

Scientific research project of hezhou university: "The intelligent home system Implementation Research based on the Internet of Things technology” (No 2014YBZK10);

"Research and development of E-government platform based on mobile terminal" (No 2015ZZZK03);

"A study on the development model of cultural tourism in Hezhou city under the background of GuiTai culture tourism cooperation” (No SK13YB096 );

"The construction and practice of the teaching system of platform and module in Tourism Management Specialty of HeZhou University” (No 2013JGA245);

Reform in Education project of hezhou university: "Internet of things"(No hzxytszy201501); "Research on application personnel training model of Communications for SMEs"(No hzxyjg201525);

Master degree discipline construction scientific research and Cultivation Project: "Research on the social work service of the teenagers' Network Addiction”(No 2015SHGZ005) \&\&“Research on the intelligent development of rural tourism in Guangxi based on the Internet of things" (No 2015MTA16); 
Nanling corridor of ethnic culture research base of Open Fund Project: "Nanling National corridor costumes digital display design” (No 2015kf27);

\section{References}

[1] Zhang Ning, Zhao Yisong, Su Limin, Xue Yongyi, Zhang Xuefen, Computer and Communications Networks for Teaching Reform of Applied Talents [J]. Computer Education.2015.

[2] Qu Haicheng, Guo Wei, Liang Xuejian, Software Engineering Talents "Enterprise Customization” Training Mode Research [J]. Computer Education.2015.

[3]Tian Weixin, Zhou Xuejun Base on the Practice of the Internet of Things Engineering Innovative Personnel Training Mode [J]. Computer Education.2015.

[4]Wang Hailong, Zhang Shuqin, Liu Weiguang Internet of Things Talents Research and Exploration[J]. Computer Education.2015. 